\title{
Research on the impacts of Ports' construction on regional economic development
}

\author{
ZHANG Yan ${ }^{1,2}$, WEN Shu-hui ${ }^{1}$ \\ (1. Faculty of Management and Economics, Kunming \\ University of Science and Technology, Kunming \\ Yunnan 650093, China; \\ zy53908679@163.com
}

\begin{abstract}
The integration of regional economic whose rapid development increase the construction speed and scale of the port of economic zone is becoming the main trend of China's economic development. In addition, the development and construction of the port has also contributed to the long-term healthy development of the regional economy. This paper establishes a model to analyze the complex relationship between the port' construction and regional economic development. The paper selects seven ports in different area including ports of Shenzhen, Dalian and Shanghai etc. as objects to study, carrier capacity, operating data and the corresponding macroeconomic data in the region within 10 years of ports as a data source, and the cross-sectional data model to analyze raw data obtained. The research results show that the port capacities will impact regional economic development and regional economic development will affect the speed and scale of the construction of the ports. But the interaction effect of ports' construction conditions and regional economic development speed have time lag, and the growth rate of port building scale are more than the expected level of regional economic development result in excess capacity of part of the ports.
\end{abstract}

Keywords-regional economy; ports' construction; cross section data model

\section{I.INTRODUCTION}

The integration of regional economic is becoming the main trend of China's economic development. Since the reform and opening up, relying on the regional advantages, the coastal areas of China make a priority for the world development opportunities, and the form two major economies areas with superior economic strength: the Pearl River Delta and Yangtze River Delta. As the traditional political and cultural center, Beijing, Tianjin and Hebei become the third largest economy region ${ }^{[1]}$. After the formation of the three major economic regions, the economic development has been speeded up remarkably, the marketing process has been accelerated, exchanges of funds, personnel, information and technology in these areas have become frequent, and social division of labor has become more refined while transportation network has the higher coverage

With the vigorous development of the regional economy, the port' construction must match the development process of regional economic integration. But there are several problems exist in the regional economic development and port' construction. First of all, the port' construction of coastal areas and regional

\author{
XIAO Zhi-wen ${ }^{2}$, CHENG Sheng-dong ${ }^{2}$ \\ 2. Institute of Agricultural Economy and Information, \\ Yunnan Academy of Agricultural Sciences, Kunming \\ Yunnan 650205, China) \\ zy53908679@163.com
}

economic development are uncoordinated. From 2006 to 2010 , the trend of economic growth and earnings growth of ports of the three economic regions in China are shown as Figure 1.

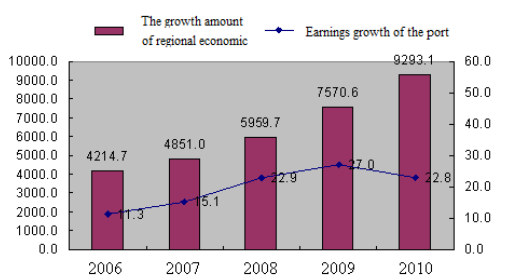

Figure 1 the trend of economic growth and earnings growth of ports in economic areas

As it can be inferred from Figure 1, the three regional economies has maintained a growth rate more than ten, and the port earnings growth downward trend appeared in 2010.

Second, there are complex effect between port' construction and regional economic co-ordination. Therefore, it is difficult to predict the impacts of port' construction planning on regional economic development. Currently, there are great gap between the scales of port, the economic development and capacity of port in different coastal region. The comparison of the containers capacity in the examples is shown in Figure 2.

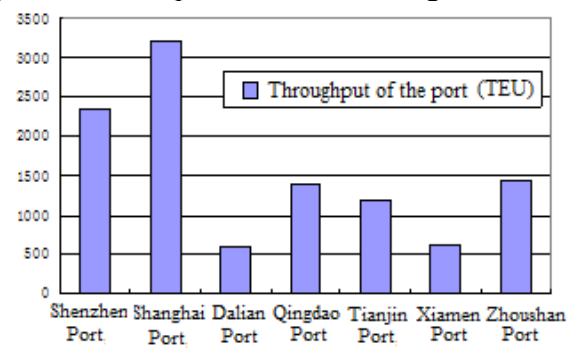

Figure 2 The comparison of capacity of containers in the example

The construction plan and function of ports should base on the economic development. Now the economic development of China is influenced by the changes aboard obviously, so the forecast of potential of regional economic development has become a problem which may lead to the time lag in the ports' construction ${ }^{[2]}$. Port capacity shortage may limit the development of the regional economy, and excess capacity of ports may reduce the growth of regional economic. Therefore, the impact of port' construction on regional economic development becomes a new hotspot. 


\section{II.REVIEW OF THE RELATION OF PORT' CONSTRUCTION AND REGIONAL ECONOMIC.}

In recent years, lots of research emerged in China reveal the mutual impacts between ports' construction and the economic development. Most of the research results show that the ports' construction promote regional economic development and enhance development potential of regional economic. In literature ${ }^{[3]}$, Zhang Hong points out that the port is the central of the economic development of coastal areas, the important part of the regional economy and regional economic development has high demand for port. The research results show the coordination relationship of long-run equilibrium between the economic growth of Shanghai and Shanghai Port. The study through the analysis of the mechanism how impacts generated describes the inherent relationship between port development and regional economic development. In literature $^{[4]}$, Du Congyuan proposes that regional economic development is an important part in design and planning of ports. The results points out that the port' construction in Hangzhou significantly behind that of the Yangtze River Delta region and the significant correlation exist between the port' construction and regional economic development. Then, Sun Kaiyan reaches a same conclusion. The investment in Tianjin Port by Tianjin government promotes the economic development. Become the pillars of its development and the strong support of the Government of the aspects of the human and material resources of the Tianjin Port and strong support (such as Human and material resources, etc.) from government is the pillars of its development ${ }^{[5]}$. Huang Jie points out that accompanying the rapid development of China's macro-economic, the capacity of coastal ports has been basically meet the development needs of the national economy, at the same time there are complex internal relations between throughput of coastal ports and national economic development ${ }^{[6]}$.

\section{III.RESEARCH MODEL OF THE IMPACT OF PORTS' CONSTRUCTION ON THE DEVELOPMENT OF REGIONAL ECONOMIC}

\subsection{Data Source}

In order to enhance the reliability and accuracy of the results, the paper selects seven ports located in different region as study objects: Shenzhen Port, Dalian Port, Shanghai Port, Tianjin Port, Qingdao Port, Xiamen Port and Zhoushan Port. The carrier capacity, the operating data and macroeconomic data in 2002-2012 of the corresponding region of the ports are chosen as the data source.

\subsection{The variables of the model}

This paper uses dependent variable y to represent annual growth rate of Macroeconomic of the region where the sample ports located, independent variables $\mathrm{x} 1, \mathrm{x} 2, \mathrm{x} 3$ and $x 4$ to represent capacity, change rate of the scale, the annual rate of return and net profit of the ports.

\subsection{Mathematical model}

In this paper, the cross-sectional data model is adopted to analyze the sample data, the specific formula is as follow:

$$
\begin{gathered}
\mathrm{y}_{\text {in }}=\lambda_{\text {in }} e+x_{i n} \beta_{\text {in }}+\delta_{\text {in }} \\
i=1,2, \ldots, N, \mathrm{n}=1,2, \ldots, N \quad
\end{gathered}
$$

In formula $3.1 \mathrm{~m}$ dependent variable $\mathrm{y}_{\text {in }}$ represents the data variable of the macro economic development of the sample region in the i-th year. Independent variable $x_{i}$ is the constructing situation, $\lambda_{i n}$ is a constant of cross-sectional data model, $\beta_{\text {in }}$ is the coefficient of the independent variable and $\delta_{i n}$ is the error of random variables independent from each other. Formula 3.1 can be described as regression form of matrix:

$$
\left(\begin{array}{c}
\mathrm{y}_{1} \\
y_{2} \\
\vdots \\
y_{N}
\end{array}\right)=\left(\begin{array}{c}
\lambda_{1} e \\
\lambda_{2} e \\
\vdots \\
\lambda_{N} e
\end{array}\right)+\left(\begin{array}{cccc}
x_{1} & 0 & \cdots & 0 \\
0 & x_{2} & \ddots & \vdots \\
\vdots & \ddots & \ddots & 0 \\
0 & \cdots & 0 & x_{N}
\end{array}\right)\left(\begin{array}{c}
\beta_{1} \\
\beta_{2} \\
\vdots \\
\beta_{N}
\end{array}\right)+\left(\begin{array}{c}
\delta_{1} \\
\delta_{2} \\
\vdots \\
\delta_{N}
\end{array}\right)
$$

The difference of dependent variable can be calculated as follow

$$
\begin{aligned}
& \mathrm{RSS}=\mathrm{y}_{i n}-\tilde{\mathrm{y}}_{i n} \\
& \text { If } W_{x x, i}=\sum\left(x_{i t}-\overline{x_{i}}\right)\left(x_{i t}-\overline{x_{i}}\right)^{\prime} \\
& W_{x y, i}=\sum\left(x_{i t}-\overline{x_{i}}\right)^{\prime}\left(y_{i t}-\overline{y_{i}}\right) \\
& W_{y y, i}=\sum\left(y_{i t}-\overline{y_{i}}\right)^{2}
\end{aligned}
$$

The residual square sum of the model is calculated as

$$
S=W_{\text {yy }}-W_{x y}^{\prime} W_{x x}^{-1} W_{x y}
$$

\section{THE RESEARCH RESULTS OF IMPACT OF PORT' CONSTRUCTION ON REGIONAL ECONOMIC DEVELOPMENT}

\subsection{Description TABLE 1 DESCRIPTIVE RESULTS}

\begin{tabular}{|l|l|l|l|}
\hline \multicolumn{4}{|l|}{ Dependent Variable: $\mathrm{Y}$} \\
\hline \multicolumn{4}{|l|}{ Included observations: 70} \\
\hline \multicolumn{4}{|l|}{ Convergence achieved after 3 iterations } \\
\hline R-squared & 0.7271 & Mean dependent var & 5.4231 \\
\hline Adjusted & 0.4914 & S.D. dependent var & 1.3214 \\
\hline
\end{tabular}




\begin{tabular}{|l|c|c|c|} 
R-squared & & & \\
\hline S.E. of regression & 1.7216 & Akaike info criterion & 3.7018 \\
\hline Sum squared resid & 13.3324 & Schwarz criterion & 2.4142 \\
\hline Log likelihood & -29.0653 & Hannan-Quinn criter. & 3.2286 \\
\hline F-statistic & 2.3159 & Prob(F-statistic) & 0.5023 \\
\hline
\end{tabular}

In the research, the value of Akaike info criterion, Schwarz criterion and Hannan-Quinn criter are 3.7018, 2.4142 and 3. 2286. We can infer that the model in this paper is validated by Akaike Information Criterion、 Schwarz Information Criterion and Hannan-Quinn Information Criterion. The average variance and standard deviation of dependent variable y are 5.4231 and 1.3214 which indicate the ports' construction has obvious impacts on the development of regional economic.

\subsection{The analysis of results}

TABLE 2 THE IMPACTS OF PORTS' CONSTRUCTION ON THE DEVELOPMENT OF REGIONAL ECONOMIC

\begin{tabular}{|c|c|c|c|c|}
\hline \multicolumn{5}{|c|}{ Dependent Variable: $Y$} \\
\hline \multicolumn{5}{|c|}{ Sample: 170} \\
\hline \multicolumn{5}{|c|}{ Included observations: 70} \\
\hline Variable & Coefficient & Std. Error & t-Statistic & Prob. \\
\hline$C$ & 7.0253 & 7.6719 & 0.9153 & 0.1714 \\
\hline$X 1$ & -2.2643 & 0.8846 & -2.5777 & 0.4763 \\
\hline$x 2$ & -2.8442 & 1.4535 & 2.5923 & 0.0175 \\
\hline$X 3$ & 2.8791 & 0.2971 & 1.9514 & 0.0137 \\
\hline$X 4$ & 0.9265 & 1.1502 & 0.8660 & 0.0210 \\
\hline
\end{tabular}

It can be inferred from Table 4.2 that the results of variables $x 2, x 3$ and $x 4$ are in the $95 \%$ confidence interval indicating the high reliability of the results. The regression coefficients of $x 1$ and $x 2$ are negative indicating that the capacity of coastal ports is surplus and the expansion of capacity and scale of the port may reduce the development of economic in this area. The coefficient of variables $\mathrm{x} 3$ and $\mathrm{x} 4$ are positive that mean the trends of gains and economic development of the port are consistent. The growth of regional economic will increase the annual revenue and net profit of ports that means the development of regional economic promotes the profits of ports. Based on the findings it can be found that the growth of port capacities promote the development of regional economic, and regional economic development affect the speed and scale of the construction of the port. But there is time lag in the mutual impacts of ports' construction and the development of regional economic, which can explain the phenomenon that the scale growth of port' construction over the level of regional economic development expected will lead to excess capacity. The actual value, the estimated value and the residual of the dependent variable in the research model is shown as Figure 3

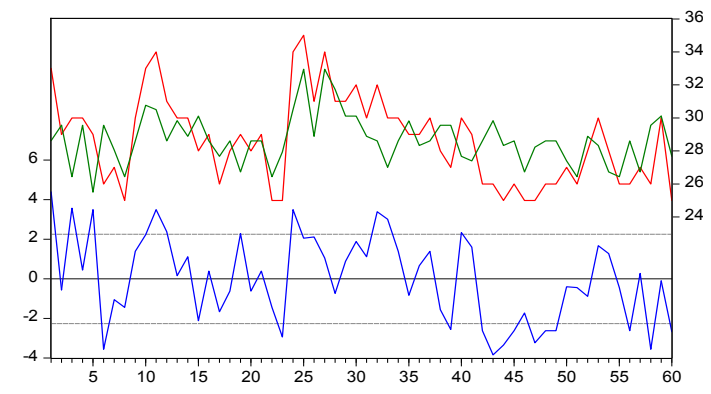

Figure 3 The actual value, the estimated value and the residual of the dependent variable

As can be inferred from Figure 3, lag differences exist in the trends of port constructing and regional economic, but both port constructing and regional economic maintain the same overall trend. Therefore, we should pay attention to the following points in port' construction and regional economic planning:

First, combining economic development and port' construction process, we need to actively carry out the research of early warning for port' construction. China's economic development with distinct Chinese characteristics, the thinking of planned economy period leaves in the current social and economic construction and planning of regional economic development. Therefore, in the critical period of ports' construction, a cluster early warning model for regional port should be built to prevent blind ports constructing and scale expanding.

Second, we should fully learn the experiences and lessons of the port' construction in the United States, Japan and South Korea and other countries using the latest research results of the management science and econometrics theory to build similar forecast model for port throughput. Then according to the current situation of China's regional economic development, we clear the dependence of the ports for different industries, establish a plan to support regional industry, and form a regional industry alliance to enhance transportation needs, thus promote transport supporting management and improve management level of ports.

Finally, the government and port authorities should make fully rational use of port resources, improve the operational efficiency of the port, and build port economy zones so as to promote the port economy the pillar industries of the regional economic; make great efforts to develop the port supporting service system, such as import and export inspection and quarantine services, so as to enable enterprises to get fast and convenient services at and improve the speed and efficiency of the circulation of the resources and products in the region, thus contributing to the improvement of port services system.

\section{V.CONCLUSIONS}

Since the reform and opening up, along with the strong construction of the port in recent years, the construction of China's coastal ports have significant impacts on regional economic development. Avoiding 
blind scale expansion of port' construction and coordinating of port' construction and regional economic development are conducive to the sustainable development of economic, help to improve the potential for regional economic development, and promote and maintain the healthy and sustainable development of coastal areas.

\section{REFERENCES}

[1] Xu Chuanyun, Zhang Yang, Yang Dan, "Ontology based Image Semantics Recognition using Description Logics", IJACT, Vol. 3, No. 10 , pp. $1 \sim 8,201$
[2] Huozhen Hu, Jinwen Tian, Guangming Dai, Maocai Wang, "A New Method of Tank Detection for SAR Images", JCIT, Vol. 6, No. 11, pp. $441 \sim 449,201$

[3] Suoju He, Yuan Gao, Jiajian Yang, Yiwen Fu, Xiao Liu, "Creating Challengeable and Satisfactory Game Opponent by the Use of CI Approaches", IJACT, Vol. 2, No. 1, pp. $41 \sim 63,2010$

[4] Yoshio KAKIZAKI and Hidekazu TSUJI, "A Decentralized Attribute Management Method and its Implementation", IJIPM, Vol. 3, No. 1, pp. $61 \sim 69,201$

[5] WU Lan. Based on The Variety Constraint Model of Remote Education Database Query Optimization Algorithm[J]. Bulletin of Science and Technolog, 2013,1(29):155-160.

[6] Tanova, C., Holtom, B.Using. Job Embeddedness Factors to Ex-plain Voluntary Turnover in 4 European Countries[J]. International Journal of Human Resource Management, 2008, 9: 1553-1568. 